DE

M E D I C I N A

T R O P I C A L

$\mathrm{DE}$

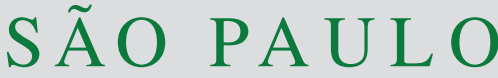

JOURNAL OF THE SÃO PAULO INSTITUTE OF TROPICAL MEDICINE

${ }^{1}$ Universidade Federal dos Vales do Jequitinhonha e Mucuri, Departamento de Ciências Biológicas, Diamantina, Minas Gerais, Brazil

2Universidade Estadual de Montes Claros. Programa de Pós-Graduação em Ciências da Saúde, Montes Claros, Minas Gerais, Brazil

${ }^{3}$ Universidade Estadual de Montes Claros. Departamento de Saúde Mental e Saúde Coletiva, Montes Claros, Minas Gerais, Brazil

${ }^{4}$ Prefeitura Municipal de Montes Claros. Centro de Controle de Zoonoses, Montes Claros, Minas Gerais, Brazil

${ }^{5}$ Prefeitura Municipal de Montes Claros, Secretaria Municipal de Saúde, Montes Claros, Minas Gerais, Brazil

${ }^{6}$ Universidade Estadual de Montes Claros. Programa de Pós-Graduação em Geografia, Montes Claros, Minas Gerais, Brazil

Correspondence to: Renata Luiz Ursine Universidade Federal dos Vales do Jequitinhonha e Mucuri, Departamento de Ciências Biológicas, Rodovia MGT 367 km 583, n 5.000, Alto Jacuba, 39100-000, Diamantina, MG, Brazil

Tel: $+55383532-1200$

E-mail: reursine@gmail.com

Received: 18 August 2020

Accepted: 7 December 2020

\section{American Tegumentary Leishmaniasis in an endemic municipality in the North of Minas Gerais State: spatial analysis and socio-environmental factors}

Renata Luiz Ursine ${ }^{\circledR 1,2}$, Marília Fonseca Rocha ${ }^{\circledR 3,4}$, Joel Fontes de Sousa ${ }^{\circledR 4}$, Ronaldo Cardoso dos Santos ${ }^{\circledR 4}$, Marcelo Dias Soares ${ }^{\circledR 4}$, Maria Suely Fernandes Gusmão ${ }^{\circledR 2,5}$, Marcos Esdras Leite ${ }^{\circledR 6}$, Thallyta Maria Vieira ${ }^{\circledR 2}$

\section{ABSTRACT}

American Tegumentary Leishmaniasis (ATL) is endemic in the municipality of Montes Claros, Minas Gerais State. The use of geotechnology such as spatial statistics and remote sensing has contributed to a better understanding of the eco-epidemiology of diseases, and consequently a better definition of control strategies. This study aimed to analyze the spatial distribution of probable sites of cases of ATL infection (2007-2011) in the municipality of Montes Claros and to identify related socio-environmental factors. Data on ATL cases notification were obtained from the Municipal Health Department of Montes Claros. The annual incidence of ATL in the municipality was calculated and the probable sites of infection were georeferenced. Crude Rate and the Local Empirical Bayesian Rate were calculated with census sectors considered as the unit of analysis. The Normalized Difference Vegetation Index (NDVI) was calculated from LANDSAT 5 TM images. The spatial association between the crude rate of ATL and the NDVI of the census tracts was evaluated using the Local Bivariate of Moran I. The socio-environmental aspects of household structures were assessed based on a structured questionnaire. The incidence of ATL in the evaluated period ranged from 6.2 to 16.6 cases/100,000 inhabitants. The highest rates of ATL occurrence were found in the census sectors located in the rural area and in the peripheral census sectors in the city. Through the Empirical Bayes Smoothed Rate map, it was found that in the peripheral areas of the city, the rates of ATL occurrence were lower than in the rural area and their values decreased as they approach the city center. Local Bivariate of Moran I showed a positive correlation between NDVI and crude ATL rates, with significant high-high clusters observed in the rural area and in the census sectors in the Western peripheral area of the city that have experienced an urban expansion concomitant to the period investigated. In most homes of people affected by the disease, there were domestic animals and organic matter in the peridomicile. In addition, a high percentage of individuals affected by ATL reported the presence of rodents circulating near their homes. In conclusion, it is possible that the disorderly expansion process in the city of Montes Claros favored the establishment of the ATL periurban and urban transmission cycle. These regions deserve special attention from health surveillance to combat this zoonosis.

KEYWORDS: Environmental health. One health. Spatial analysis. Cutaneous Leishmaniasis. American Tegumentary Leishmaniasis. Eco-epidemiology.

\section{INTRODUCTION}

American Tegumentary Leishmaniasis (ATL) is a neglected disease caused by different species of protozoa of the genus Leishmania, which are transmitted 
by contaminated female sandflies ${ }^{1}$. The disease clinically manifests through cutaneous, mucosal and mucocutaneous lesions that can cause bodily disfigurement, trigger social stigma and suffering in affected people ${ }^{2}$.

Annually, it is estimated that between 0.6 and 1 million new ATL cases occur in the world, with more than $90 \%$ of them occurring in the Americas, the Mediterranean basin, the Middle East and Central Asia ${ }^{1}$. In Brazil, there are records of ATL cases in all the federative units, representing a serious public health problem due to its high morbidity ${ }^{3}$.

Although ATL occurs predominantly in rural areas, with clusters in forested areas and reserve settlements neighborhoods ${ }^{4}$, the epidemiology of this disease is complex and dynamic, since it presents a variation of factors associated with transmission cycles, that are influenced by a range of environmental, climate and socioeconomic conditions ${ }^{5,6}$. A better understanding of the eco-epidemiology of leishmaniasis, through the spatial characterization of the environments where ATL occurs in association with socioeconomic indicators, can contribute to predict areas at risk, as well as the development of control measures with greater chances of success ${ }^{7}$.

The Northern mesoregion of the Minas Gerais State corresponds to one of the main areas of ATL occurrence ${ }^{7-9}$. Thus, this study aimed to analyze the spatial distribution and socio-environmental factors related to the areas of ATL occurrence between 2007 to 2011, in the municipality of Montes Claros in the North of Minas Gerais State, Brazil.

\section{MATERIALS AND METHODS}

This is a descriptive ecological study, with data collected retrospectively and prospectively. The study population consisted of autochthonous cases of ATL occurring between 2007 and 2011 in the municipality of Montes Claros.

\section{Study area}

The study was carried out in the municipality of Montes Claros (between geographical coordinates $16^{\circ} 04^{\prime} 57^{\prime \prime}$ \& $17^{\circ} 08^{\prime} 41^{\prime \prime}$ latitude South, and $43^{\circ} 41^{\prime} 56^{\prime \prime} \& 44^{\circ} 13^{\prime} 1$ " longitude West of Greenwich), located in the North of Minas Gerais State, with an area of 3,568,941 $\mathrm{km}^{2}$, an estimated population of 409,341 inhabitants and a human development index of $0.770^{10}$. Montes Claros is considered the municipality with the sixth largest number of inhabitants in Minas Gerais State ${ }^{10}$, and is the main city in the Northern region of the State; this municipality stands out for hosting important universities and industries, being a cultural and regional reference ${ }^{11}$.
Montes Claros is located within the Cerrado region, presenting with a predominant phytophysiognomies Cerrado stricto sensu and dry forest ${ }^{12}$. According to the climate classification of Koppen, the region presents a tropical climate with dry summer $(\mathrm{As})^{13}$.

\section{Obtaining the data}

Data on notification of human cases of ATL occurring between 2007 to 2011 in the municipality of Montes Claros were acquired from records of the Notifiable Diseases Information System (Sistema de Informacao de Agravos de Notificacao - SINAN) at the Municipal Health Department of Montes Claros. The following data were collected: name, gender, date of birth, date of notification, self-declared skin color, education, area of residence (rural or urban), type of clinical manifestation, evolution of the case, address, Probable Sites of Infection (PSI) and occupation.

The PSI were georeferenced using a Global Positioning System (GPS) navigation device Garmin Etrex ${ }^{\circledR}$ (Garmin Ltd., Olathe, USA). People notified with ATL filled out a structured form with questions related to the environmental conditions at home, peridomicile, occupational and leisure activities. The questionnaire was structured with the following variables: name; date of birth; gender; residence zone (rural/urban); presence of domestic animals at home (chickens, dogs, cats, horses, cattle, pigs); accumulation of organic matter in the house (presence/absence); location of sanitary facilities (intradomicile/extra-domicile); characteristics present in the peridomestic environment (alembic, flour mill, open sewer, kitchen garden, pigsty, river or stream, fruit trees, hen house, crops); wild animals reported to circulate nearby (rodents, marsupials, primates, wild canids, edentates), occupation (students, domestic activities, rural worker, teacher, others, not applicable), leisure activity carried out by the participant when contracted the disease (none, fishing, climbing, other); frequency of leisure activities (weekly, monthly, quarterly, not applicable).

Inclusion criteria were confirmed cases of the disease by laboratory tests (Direct parasitological diagnosis and/or Montenegro skin test and/or histopathology) and/or by epidemiological clinical characteristics), and being autochthonous to the municipality of Montes Claros. Exclusion criteria were cases whose records were illegible or incorrectly filled out, as well as cases not found, and individuals who did not accept to participate in the research. Data were collected between April 2012 and June 2014.

\section{Geographic and statistical analyzes}

The annual incidence of ATL in the municipality was 
calculated based on information from the IBGE (Instituto Brasileiro de Geografia e Estatistica), considering data from the 2007 population count, the demographic census of 2010 , and for the other years (2008, 2009 and 2011), population estimates were used ${ }^{14}$.

The Crude Rate and the Local Empirical Bayesian Rate were calculated (per 100,000 inhabitants), with the census sectors being the unit of analysis. For these calculations, the 2010 demographic census counts were considered as at risk populations ${ }^{14}$. The Crude Rate is the simple ratio of the events with respect to the population at risk, whereas the Local Empirical Bayesian Rate also considers the number of events in the population at risk, but it does the smoothing for random fluctuation, which improves the precision of the crude rate by borrowing strength from the other neighboring observations ${ }^{15}$. To smooth this rate, the neighborhood matrix of the queen type was used.

The Normalized Difference Vegetation Index (NDVI) was adopted to assess any correlation between the vegetation density and the spatial distribution of ATL cases in the municipality of Montes Claros. The NDVI was calculated with the aid of the QGIS ${ }^{\circledR}$ program (version 3.4 Madeira, QGIS Development Team) using bands 3 (red) and 4 (near infrared) of the Thematic Map sensor on board the LANDSAT 5 satellite, collection 2, level 2. The NDVI was calculated using the following equation:

$$
N V D I=\frac{(i v p-v)}{(i v p+v)}
$$

where, $i v p$ is the reflectance in the near infrared and $v$ is the reflectance in the red.

The images used to calculate the NDVI corresponded to orbit 218, points 072 and 071, collected on August 25, 2007, September 12, 2008, September 15, 2009, February 22, 2010 and September 21, 2011. These images were selected because they have a low cloud cover in the study area. The satellite products were obtained from the United States Geological Survey ${ }^{16}$. The NDVI was calculated for each image and, for analysis purposes, the index average over the five years was used.

The spatial correlation between the ATL crude rate and the average NDVI values of the census sectors was assessed using the Local Bivariate of Moran I (Bivariate LISA). This index assesses the relationship between the value of a variable at the location and the value of the second variable in its neighborhood ${ }^{17}$. For this analysis, the neighborhood matrix of the queen type was used. The Bivariate LISA was validated using the pseudo-significance test based on 999 random permutations, thus allowing to establish the statistical significance of the obtained result. The GeoDa software, version 1.16.0.61 (University of Chicago,
Chicago, USA) was used to calculate the crude rate, the Local Bayesian Empirical Rate and the Bivariate LISA.

Simple (n) and relative (\%) frequencies were estimated for all the variables collected. Subsequently, a bivariate analysis was carried out between the area of residence and the other sociodemographic (gender, age range, skin color, education, occupation), and between the area of residence and socio-environmental variables (presence of domestic animals at home, accumulation of organic matter in the house, location of sanitary facilities, characteristics present in the peridomestic environment, wild animals reported to circulate nearby) using the Pearson's $X^{2}$ test, considering a significance level of 0.05 and the SPSS statistical software, version 22.0 (IBM Corp, Armonk, NY, USA).

\section{Ethical aspects}

This study was approved by the Research Ethics Committee of the State University of Montes Claros (UNIMONTES), process number 10034, complying with Resolution 466/2012 of the National Health Council ${ }^{18}$.

\section{RESULTS}

Between 2007 and 2011, 320 cases of ATL were reported in the municipality of Montes Claros, Minas Gerais, of which 203 cases were included in the study. The average incidence rate of ATL in the evaluated period was 11.38 cases $/ 100,000$ inhabitants and the annual values of this rate are shown in Figure 1.

The highest crude rates of ATL occurrence were found in the census sectors in the rural area and in the peripheral census sectors in the city (Figure 2A). While the highest rates of ATL occurrence smoothed by the Empirical Bayesian method were found in the rural area, without a significant variation with respect to the peripheral urban area. In the city, the values of these rates decreased from the periphery to the center of the city, with the exception of some sectors (Figure 2B). The analysis of Bivariate LISA showed a positive correlation between crude ATL rate and NDVI (Moran I: 0.385). High-high clusters were observed in the peripheral census sectors in the Western region of the city and in rural districts. Further information on the Bivariate LISA analysis is shown in Figure 3.

Regarding the clinical form, 199 (98.03\%) individuals manifested the cutaneous form, two $(0.99 \%)$ mucous, and two $(0.99 \%)$ cutaneous-mucous. Most patients evolved to cure $(\mathrm{n}=199 ; 98.03 \%)$, with one death due to ATL $(0.49 \%)$; one patient abandoned treatment $(0.49 \%)$ and this information was missing from two records $(0.99 \%)$. 


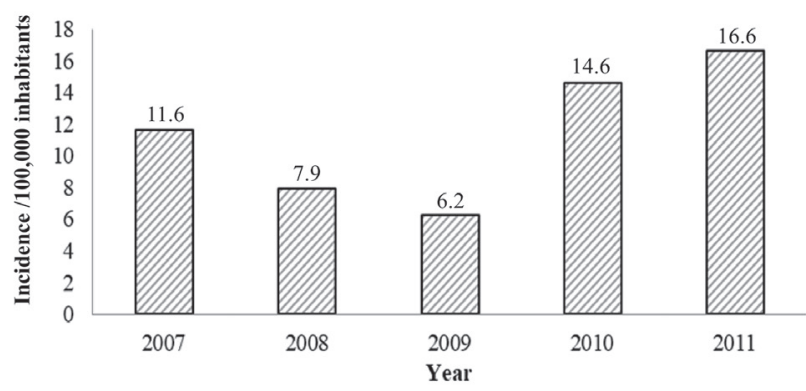

Figure 1 - Incidence of American Tegumentary Leishmaniasis between 2007 and 2011, in the municipality of Montes Claros, Minas Gerais State. Incidence rate $=$ (number of cases/ number of inhabitants) x 100,000. Sources: Brazilian Institute of Geography and Statistics and Municipal Health Department of the municipality of Montes Claros, Minas Gerais State.

The largest number of ATL cases occurred in males, average age of 35.79 years (standard deviation \pm 20.29 ), self-declared as brown (mixed ethnicity), with a low level of education, living in the urban area. Significant differences were observed in terms of educational level $\left(X^{2}=15.484(4) ; \mathrm{p}=0.004\right)$ and occupational profile of those affected $\left(X^{2}=33.837 ; \mathrm{p}=0.000\right)$ in urban and rural areas. Other sociodemographic information is described in Table 1.

When comparing the frequencies of domestic animals, accumulation of organic matter and wild animals circulating nearby (except rodents and marsupials), between the environments of ATL occurrence (rural/urban), significant differences were found between the observed and expected counts. In rural areas, observed counts of these variables were above the expected count. Other characteristics related to these environments are described in Table 2.

Among the 203 investigated individuals, 165 (81.28\%) stated that they were not carrying out leisure activities at the time of infection and four (1.97\%) did not inform about leisure activities. The 34 (16.75\%) who said they have had leisure activities mentioned fishing $(\mathrm{n}=2 ; 5.88 \%)$, climbing $(\mathrm{n}=8 ; 23.53 \%)$ and other activities $(\mathrm{n}=24 ; 70.58 \%)$ related to walking in forested environments. Regarding their frequency, 19 individuals said it was weekly, two monthly, one quarterly, and 12 did not report the frequency.

\section{DISCUSSION}

The average incidence rate of ATL in Montes Claros in the evaluated period was higher than the value reported in Minas Gerais State (approximately 6.8 cases $/ 100,000$ inhabitants) $)^{8}$, with increasing values between 2009 and 2011. In relation to the spatial distribution of ATL crude rates, most census sectors in the rural area showed high values, whereas in the city the highest rates were found in peripheral regions, mainly in the Western region, where there were profound environmental changes as a consequence of urban expansion concomitant with the investigated period ${ }^{19,20}$. Through the Empirical Bayes Smoothed Rate map, it was verified that in the peripheral areas of the city, the rates were lower than in the rural area
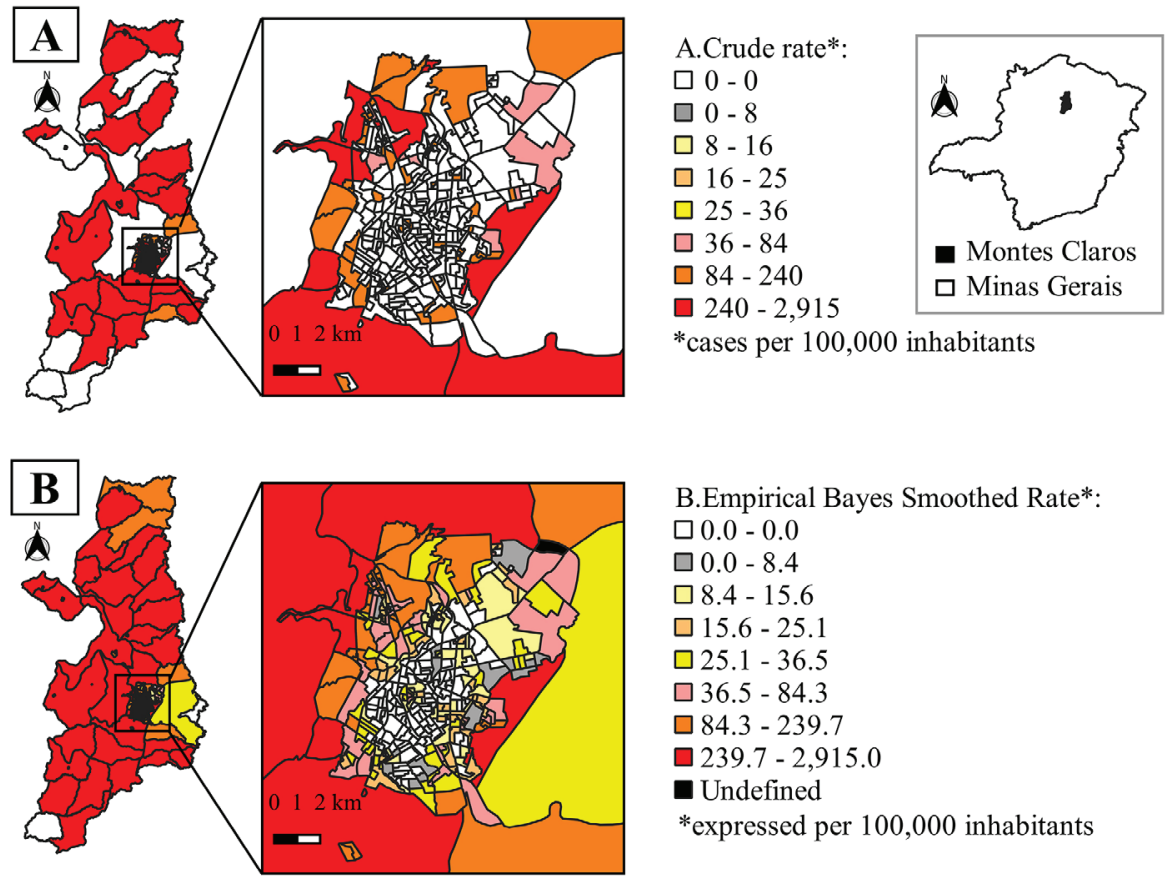

B.Empirical Bayes Smoothed Rate*:

$\square 0.0-0.0$

$\square 0.0-8.4$

$\square 8.4-15.6$

$\square 15.6-25.1$

$\square 25.1-36.5$

$\square 36.5-84.3$

$\square 84.3-239.7$

$\square 239.7-2,915.0$

- Undefined

*expressed per 100,000 inhabitants

Figure 2 - A) Crude Rate Map for cases of American Tegumentary Leishmaniasis in Montes Claros, between 2007 and 2011 ; B) Empirical Bayes Smoothed Rate Map for cases of American Tegumentary Leishmaniasis in Montes Claros, between 2007 and 2011. The limits represent the census sectors according to the 2010 Census. 

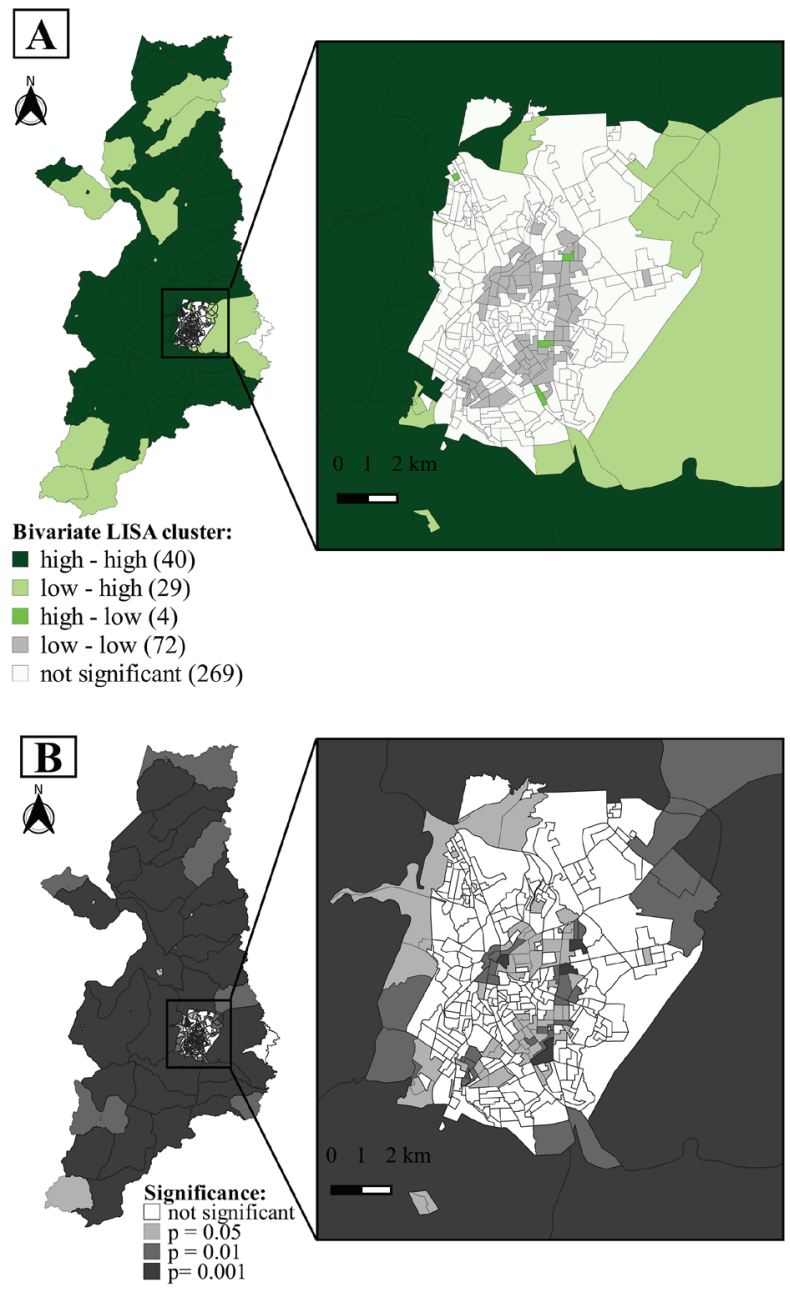

Figure 3 - Spatial autocorrelation between American Tegumentary Leishmaniasis and Normalized Difference Vegetation Index of the census sectors in Montes Claros, between 2007 and 2011: A) Bivariate LISA Map; B) Representation of areas with significant values of Bivariate LISA. The limits represent census sectors according to the 2010 Census.

(except in some sectors) and that their values decreased as they approached the city center, suggesting a process of urbanization of the disease.

In a systematic review, significant associations were found between high NDVI and ATL occurrence in 55\% of the studies that used this variable ${ }^{6}$. In the present study, a significant positive correlation was also found among these variables, of the high-high type in most sectors of the rural area and in the peripheral census sectors in the Western region of the city. This region of the city has green areas with remnants of native forest and is connected to important forest reserves, such as Lapa Grande State Park and Serra do Mel, also known as Serra da Sapucaia ${ }^{21}$, which eliminated part of its forest for building allotments and installing condominiums ${ }^{19}$. These forests are possible important shelters of reservoirs and vectors of Leishmania species that cause ATL and the ecological imbalance resulting from urban expansion may have contributed to the transmission of the disease in the region.

When assessing the form of clinical manifestation, as observed in other studies ${ }^{22,23}$, most individuals presented with the cutaneous form. The predominance of treated cases evolving to cure was expected since ATL has a high morbidity, but low mortality ${ }^{24}$. According to WHO, more than $80 \%$ of the deaths of patients with cutaneous and mucosal leishmaniasis that occurred in recent years were in patients over the age of 50 years, which may be associated with possible complications caused by the use of medication and underlying diseases ${ }^{24}$. In the present study, the patient who died was an elderly (67 years old) who used the pentavalent antimonial, a drug that is not recommended as the first choice in patients over 50 years old due to its high toxicity ${ }^{25}$. Thus, the death of this patient may be attributed to complications caused by the drug administered in the treatment.

In the studied municipality, the highest number of ATL cases occurred among adult male individuals of working age. This profile has also been observed in other studies ${ }^{22,23,26,27}$, and some researchers attribute the vulnerability of this group to the occupational exposure in activities developed in rural areas ${ }^{28}$. However, in this study, significant differences were observed in relation to the occupational activity performed by individuals affected by ATL who lived in rural and urban areas. Most people who lived in rural areas worked in agricultural activities, however people who lived in urban areas carried out mainly activities related to commerce, industry and administrative services.

Despite the differences observed in relation to the categorical frequencies regarding the education of people who had ATL in rural and urban areas, it was found that the disease mainly affected people with low education, as was verified in other studies, ${ }^{9,22,29}$. It is believed that these individuals are more affected by ATL due to a low understanding of the risk factors related to the disease ${ }^{9}$. In addition, it is possible that the lowest level of education reflects worse socioeconomic conditions, and consequently precarious housing conditions, with an increase in exposures to household environmental risk factors ${ }^{30}$.

Regarding the analysis of houses and the peridomiciliar environment of people affected by ATL, differences were found in the frequencies of domestic animals and accumulation of organic matter when comparing the environments of ATL occurrence (rural/urban), with a higher occurrence of the disease in rural environments. However, it is important mentioning that in more than 50\% of households in urban areas, the presence of chickens, dogs and organic matter was found,, which are considered socio-environmental risk factors for ATL, as they attract sand flies to the household ${ }^{6,26,31}$. 
Table 1 - Sociodemographic profile of patients diagnosed with American Tegumentary Leishmaniasis, and residing in the municipality of Montes Claros, Minas Gerais, between 2007 and 2011.

\begin{tabular}{|c|c|c|c|c|}
\hline \multirow{2}{*}{ Variables } & \multicolumn{2}{|c|}{ Residence zone } & \multirow{2}{*}{$\begin{array}{c}\text { Total } \\
\mathrm{n}=203(100 \%)\end{array}$} & \multirow{2}{*}{ Pearson $X^{2}$} \\
\hline & Rural $(n=68)$ & Urban $(n=135)$ & & \\
\hline \multicolumn{5}{|l|}{ Gender } \\
\hline Female & 25 & 55 & $80(39.41 \%)$ & \multirow{2}{*}{$X^{2}=0.299(1) ; p=0.348$} \\
\hline Male & 43 & 80 & $123(60.59 \%)$ & \\
\hline \multicolumn{5}{|l|}{ Age Groups } \\
\hline 0 to 14 years & 11 & 24 & $35(17.24 \%)$ & \multirow{4}{*}{$X^{2}=6.339(3) ; p=0.096$} \\
\hline 15 to 19 years & 12 & 10 & $22(10.84 \%)$ & \\
\hline 20 to 59 years & 33 & 83 & $116(57.14 \%)$ & \\
\hline 60 years or more & 12 & 18 & $30(14.77 \%)$ & \\
\hline \multicolumn{5}{|l|}{ Skin Color } \\
\hline Asian & 01 & 03 & $04(01.97 \%)$ & \multirow{5}{*}{$X^{2}=4.286(4) ; p=0.369$} \\
\hline White & 10 & 29 & $39(19.21 \%)$ & \\
\hline Mixed ethnicity & 42 & 86 & $128(63.05 \%)$ & \\
\hline Black & 07 & 06 & $13(06.40 \%)$ & \\
\hline Unknown & 08 & 11 & $19(09.40 \%)$ & \\
\hline \multicolumn{5}{|l|}{ Education } \\
\hline Illiterate & 08 & 11 & $19(09.36 \%)$ & \multirow{5}{*}{$X^{2}=15.484(4) ; p=0.004$} \\
\hline Junior school & 39 & 61 & $100(49.26 \%)$ & \\
\hline High school & 20 & 37 & $57(28.08 \%)$ & \\
\hline Higher education & 00 & 17 & $17(08.37 \%)$ & \\
\hline Unknown/not applicable & 01 & 09 & $10(04.93 \%)$ & \\
\hline \multicolumn{5}{|l|}{ Occupation } \\
\hline Students & 16 & 25 & $41(20.20 \%)$ & \multirow{6}{*}{$X^{2}=33.837(5) ; p=0.000$} \\
\hline Domestic activities* & 16 & 30 & $46(22.66 \%)$ & \\
\hline Rural worker & 25 & 12 & $37(18.23 \%)$ & \\
\hline Teacher & 00 & 03 & $03(01.48 \%)$ & \\
\hline Others ${ }^{* *}$ & 10 & 56 & $66(32.51 \%)$ & \\
\hline Not applicable & 01 & 09 & $10(04.93 \%)$ & \\
\hline
\end{tabular}

Source: Municipal Health Department of the municipality of Montes Claros, Minas Gerais State. *Domestic activities = domestic worker, stays at home, retired; ${ }^{*}$ Others = administrative, commercial, industrial activities, among others, not related to the rural and wild environment.

Regarding the presence of wild animals, the proportion of individuals affected by ATL who reported the presence of primates, wild canids and edentates circulating near their homes was higher among people residing in rural areas. However, there was no significant difference regarding the frequencies of the reports of rodents and marsupials circulating in the vicinity of their homes, and a high percentage of people reported the presence of rodents in both locations. Therefore, it is possible that rodents may be serving as a constant source of food and infection for sandflies, contributing to the maintenance of a peridomestic transmissioncycle, because they are the main hosts and reservoirs of Leishmania species that cause $\mathrm{ATL}^{32}$. In
Londrina, Parana State, researchers detected synanthropic rodents naturally infected by Leishmania amazonensis, which provides new evidence of the urbanization of this etiological agent ${ }^{33}$. Thus, it is important to conduct studies that seek to investigate Leishmania spp. infection in rodents in the city of Montes Claros.

In this study, most people affected by ATL reported that they did not carry out leisure activities in a rural/wild environments at the time they were infected. However, the possibility of a recall bias should be considered, given the time interval between the infection and the information collection.

In conclusion, in Montes Claros the highest rates of ATL 
Table 2 - Characteristics of the houses and their peridomicile environment of people affected by the American Tegumentary Leishmaniasis, between 2007 and 2011, in the municipality of Montes Claros, Minas Gerais State, according to the location of the infection.

\begin{tabular}{|c|c|c|c|c|}
\hline Variables & $\begin{array}{l}\text { Rural } \\
\mathrm{N}=68\end{array}$ & $\begin{array}{l}\text { Urban } \\
\mathrm{N}=135\end{array}$ & $\begin{array}{c}\text { Total } \\
\mathrm{N}=203(100 \%)\end{array}$ & Pearson $X^{2}$ \\
\hline \multicolumn{5}{|c|}{ Presence of domestic animals in the houses } \\
\hline Chickens & 64 & 74 & $138(68.0 \%)$ & $X^{2}=32.092(1) ; p=0.000$ \\
\hline Dogs & 63 & 100 & $163(80.3 \%)$ & $X^{2}=9.859(1) ; p=0.002$ \\
\hline Cats & 57 & 65 & $122(60.1 \%)$ & $X^{2}=24.001(1) ; p=0.000$ \\
\hline Horses & 59 & 44 & $103(50.7 \%)$ & $X^{2}=53.095(1) ; p=0.000$ \\
\hline Cattle & 57 & 34 & $91(44.8 \%)$ & $X^{2}=62.870(1) ; p=0.000$ \\
\hline Pigs & 56 & 47 & $103(50.7 \%)$ & $X^{2}=40.887(1) ; p=0.000$ \\
\hline \multicolumn{5}{|c|}{ Wild animals reported to circulate nearby } \\
\hline Rodents & 64 & 118 & $182(89.7 \%)$ & $X^{2}=2.195(1) ; p=0.138$ \\
\hline Marsupials & 11 & 25 & $36(17.7 \%)$ & $X^{2}=0.170(1) ; p=0.680$ \\
\hline Primates & 62 & 96 & $158(77.8 \%)$ & $X^{2}=10.553(1) ; p=0.001$ \\
\hline Wild Canids & 11 & 09 & $20(9.9 \%)$ & $X^{2}=4.605(1) ; p=0.032$ \\
\hline Edentates & 58 & 30 & $88(43.3 \%)$ & $X^{2}=73.254(1) ; p=0.000$ \\
\hline \multicolumn{5}{|c|}{ Accumulation of organic matter in the houses } \\
\hline & 66 & 96 & $162(79.8 \%)$ & $X^{2}=18.890(1) ; p=0.000$ \\
\hline \multicolumn{5}{|c|}{ Characteristics present in the peridomestic environment } \\
\hline Alembic (still) & 26 & 12 & $38(18.7 \%)$ & $X^{2}=25.597(1) ; p=0.000$ \\
\hline Flour mill & 41 & 14 & $55(27.1 \%)$ & $X^{2}=57.060(1) ; p=0.000$ \\
\hline Open sewer & 10 & 27 & $37(18.2 \%)$ & $X^{2}=0.850(1) ; p=0.356$ \\
\hline Kitchen garden & 57 & 48 & $105(51.7 \%)$ & $X^{2}=42.193(1) ; p=0.000$ \\
\hline Pigsty & 62 & 46 & $108(53.2 \%)$ & $X^{2}=59.224(1) ; p=0.000$ \\
\hline River or stream & 46 & 60 & $106(52.2 \%)$ & $X^{2}=9.757(1) ; p=0.002$ \\
\hline Fruit trees & 64 & 81 & $145(71.4 \%)$ & $X^{2}=27.490(1) ; p=0.000$ \\
\hline Hen house & 62 & 71 & $133(65.5 \%)$ & $X^{2}=29.799(1) ; p=0.000$ \\
\hline Crops & 57 & 36 & $93(45.8 \%)$ & $X^{2}=59.511(1) ; p=0.000$ \\
\hline \multicolumn{5}{|c|}{ Location of sanitary facilities } \\
\hline Intradomicile & 57 & 108 & $165(81.3 \%)$ & \multirow{2}{*}{$X^{2}=0.890(2) ; p=0.641$} \\
\hline Extra-domicile & 06 & 18 & $24(11.8 \%)$ & \\
\hline
\end{tabular}

were found in rural districts and in the peripheral areas of the city that underwent urban expansion concurrent with the investigated period, mainly in the Western region, where there was destruction of native forest for the implementation of condominiums. These regions deserve special attention from health surveillance systems in the fight against this zoonosis. Although in smaller proportions, the cases notification in the central area of the city was also verified, suggesting the ATL urbanization in the region, however more studies are needed to understand this process. The characterization of the PSI showed the persistence of risk conditions related to the occurrence of new cases of the disease. Thus, it is important to promote health education actions from the perspective of the One health concept, so that the population understands the connection between environmental, animal and human health conditions and contributes to the environmental management of their homes in order to change the favorable conditions for the establishment of vectors and hosts.

A limitation of this study was that it did not carry out an entomological investigation. However, in entomological surveys carried out by the Zoonosis Control Center for Visceral Leishmaniasis Surveillance between February and October 2011, in the urban area of the city of Montes Claros, 1,448 specimens of Lutzomyia intermedia and 68 of $L$. whitmani were recorded (unpublished observations), 
which are important ATL vectors ${ }^{34}$. In this context, it is important to carry out studies to investigate ATL vectors in areas that showed high rates of the disease in the city of Montes Claros.

Another limitation of this study was the information bias, inherent to the use of secondary data. Among the notified patients, about $37 \%$ were excluded from the research due to inconsistencies in the notification forms (missing data, absence of address). In addition, the possibility of underreporting must be considered. Despite the limitations presented, considering that ATL continues to be a serious public health problem in this region, we believe that this research can contribute to guide control strategies and future research.

\section{ACKNOWLEDGMENTS}

We are grateful to the professionals from the Montes Claros Municipal Health Department and the Montes Claros Zoonosis Control Center who contributed to the execution of this work

\section{AUTHORS' CONTRIBUTIONS}

RLU: conception and design; data collection; performed the statistical analysis; wrote the manuscript; MFR: conception and design; data collection; approval of the final version; JFS: conception and design; data collection; RCS: data collection; MDS: data collection; MSFG: data collection; MEL: correction of the manuscript; approval of the final version; TMV: wrote the manuscript; correction of the manuscript; approval of the final version.

\section{CONFLICT OF INTERESTS}

The authors declare that there is no conflict of interest.

\section{FUNDING}

The authors declare that this study was carried out with no specific funding.

\section{REFERENCES}

1. World Health Organization. Leishmaniasis. [cited 2020 Dec 7]. Available from: https://www.who.int/news-room/fact-sheets/ detail/leishmaniasis

2. Bailey F, Mondragon-Shem K, Haines LR, Olabi A, Alorfi A, Ruiz-Postigo JA, et al. Cutaneous leishmaniasis and co-morbid major depressive disorder: a systematic review with burden estimates. PLoS Negl Trop Dis. 2019;13:e0007092.
3. Bezerra JM, Araújo VE, Barbosa DS, Martins-Melo FR, Werneck GL, Carneiro M. Burden of leishmaniasis in Brazil and federated units, 1990-2016: findings from Global Burden of Disease Study 2016. PLoS Negl Trop Dis. 2018;12:e006667.

4. Marchi MN, Caldart ET, Martins FD, Freire RL. Spatial analysis of leishmaniasis in Brazil: a systematized review. Rev Inst Med Trop Sao Paulo. 2019;61:e68.

5. Buzanovsky LP, Sanchez-Vazquez MJ, Maia-Elkhoury AN, Werneck GL. Major environmental and socioeconomic determinants of cutaneous leishmaniasis in Brazil: a systematic literature review. Rev Soc Bras Med Trop. 2020;53:e20190291.

6. Valero NN, Uriarte M. Environmental and socioeconomic risk factors associated with visceral and cutaneous leishmaniasis: a systematic review. Parasitol Res. 2020;119:365-84.

7. Temponi AO, Brito MG, Ferraz ML, Diniz SA, Silva MX, Cunha TN. Ocorrência de casos de leishmaniose tegumentar americana: uma análise multivariada dos circuitos espaciais de produção, Minas Gerais, Brasil, 2007 a 2011. Cad Saude Publica. 2018;34:e00165716.

8. Cardoso DT, Souza DC, Castro VN, Geiger SM, Barbosa DS. Identification of priority areas for surveillance of cutaneous leishmaniasis using spatial analysis approaches in Southeastern Brazil. BMC Infect Dis. 2019;19:318.

9. Pinto MO, Oliveira TM, Aguiar NA, Pinto PE, Barbosa DS, Diniz SA, et al. Profile of American tegumentary leishmaniasis in transmission areas in the State of Minas Gerais, Brazil, from 2007 to 2017. BMC Infect Dis. 2020;20:163.

10. Instituto Brasileiro de Geografia e Estatística. Brasil/Minas Gerais/ Montes Claros. [cited 2020 Dec 7]. Available from: https:// cidades.ibge.gov.br/brasil/mg/montes-claros/panorama

11. Leite ME, Brito JL. Sensoriamento remoto aplicado ao mapeamento do uso do solo urbano e de assentamentos ilegais em Montes Claros-MG. Geosul. 2012;26:99-128.

12. Borges MG, Rodrigues HL, Leite ME. Sensoriamento remoto aplicado ao mapeamento do Cerrado no Norte de Minas Gerais e suas fitofisionomias. Cad Geogr. 2019;29:819-35.

13. Alvares CA, Stape JL, Sentelhas PC, Gonçalves JL, Sparovek G. Köppen's climate classification map for Brazil. Meteorol Z. 2013;22:711-28.

14. Instituto Brasileiro de Geografia e Estatística. Estimativas de população: 2020. [cited 2020 Dec 7]. Available from: https:// sidra.ibge.gov.br/pesquisa/estimapop/tabelas

15. Anselin L. GeoDa: maps for rates or proportions. [cited 2020 Dec 7]. Available from: https://geodacenter.github.io/workbook/3b_ rates/lab3b.html

16. United States Geological Survey. Earth Explorer. [cited 2020 Dec 7]. Available from: https://earthexplorer.usgs.gov/

17. Anselin L. GeoDa: Bivariate spatial correlation: a word of caution. [cited 2020 Dec 7]. Available from: https://geodacenter.github. io/workbook/5b_global_adv/lab5b.html\#bivariate-spatialcorrelation---a-word-of-caution 
18. Brasil. Ministério da Saúde. Conselho Nacional de Saúde. Resolução No 466, de 12 de dezembro de 2012. Diário Oficial da União, Brasília, 13 jun. 2012. Seção 1.

19. França IS, Almeida MI, Oliveira RS. Dinâmica imobiliária em cidades médias: a expansão dos empreendimentos horizontais em Montes Claros/MG. Geo UERJ. 2014;1:19-38.

20. Martins AS, Leite ME. Análise do crescimento das favelas da cidade de Montes Claros - MG por imagens de alta resolução espacial. XVII Simpósio Brasileiro de Sensoriamento Remoto; 25-29 de abril de 2015; INPE, João Pessoa, PB, Brasil. p. 3715-21.

21. Leite ME, organizador. Atlas ambiental de Montes Claros/MG. Montes Claros: Unimontes; 2020.

22. Grangeiro Júnior CR, Pimentel JV, Teixeira Júnior AG, Jesus AF, Galvão TC, Souza LA, et al. American cutaneous leishmaniasis in a northeast Brazilian city: clinical and epidemiological features. Rev Soc Bras Med Trop. 2018;51:837-42.

23. Detoni MB, Lima DM, Silva TP, Machado LF, Tomiotto-Pellissier F, Costa IN, et al. Temporal and spatial distribution of American tegumentary leishmaniasis in north Paraná: 2010-2015. Rev Soc Bras Med Trop. 2019;52:e20180119.

24. Organização Pan-Americana da Saúde. Leishmanioses: informe epidemiológico das Américas. Washington: OPAS; 2019. [cited 2020 Dec 7]. Available from: http://iris.paho.org/xmlui/ handle/123456789/50505

25. Brasil. Ministério da Saúde. Secretaria de Vigilância em Saúde. Departamento de Vigilância Epidemiológica. Manual de vigilância da leishmaniose tegumentar americana. Brasília: Ministério da Saúde; 2017. [cited 2020 Dec 7]. Available from: http://bvsms.saude.gov.br/bvs/publicacoes/manual_vigilancia_ leishmaniose_tegumentar.pdf

26. Araujo AR, Portela NC, Feitosa AP, Silva OA, Ximenes RA, Alves LC, et al. Risk factors associated with American cutaneous leishmaniasis in an endemic area of Brazil. Rev Inst Med Trop Sao Paulo. 2016;58:86.
27. Oliveira A, Santil FL, Fonzar UJ. Cartografia da leishmaniose tegumentar americana (LTA) em Maringá - Paraná: 2010 a 2016. Hygeia. 2018;14:65-79.

28. Guerra JA, Guerra MG, Vasconcelos ZS, Freitas NS, Fonseca FR, Silva Júnior RC, et al. Socioenvironmental aspects of the Purus Region - Brazilian Amazon: why relate them to the occurrence of American tegumentary leishmaniasis? PLoS One. 2019;14:e0211785.

29. Melchior LA, Brilhante AF, Chiaravalloti-Neto F. Spatial and temporal distribution of American Cutaneous Leishmaniasis in Acre state, Brazil. Infect Dis Poverty. 2017;6:99.

30. Menezes JA, Luz TC, Sousa FF, Verne RN, Lima FP, Margonari C. Fatores de risco peridomiciliares e conhecimento sobre Leishmaniose visceral da população de Formiga, Minas Gerais. Rev Bras Epidemiol. 2016;19:362-74.

31. Cruz CF, Cruz MF, Galati EA. Sandflies (Diptera: Psychodidae) in rural and urban environments in an endemic area of cutaneous leishmaniasis in southern Brazil. Mem Inst Oswaldo Cruz. 2013;108:303-11.

32. Roque AL, Jansen AM. Wild and synanthropic reservoirs of Leishmania species in the Americas. Int J Parasitol Parasites Wildl. 2014;3:251-62.

33. Caldart ET, Freire RL, Ferreira FP, Ruffolo BB, Sbeghen MR, Mareze M, et al. Leishmania in synanthropic rodents (Rattus rattus): new evidence for the urbanization of Leishmania (Leishmania) amazonensis. Rev Bras Parasitol Vet. 2017;26:17-27.

34. Souza NA, Andrade-Coelho CA, Silva VC, Peixoto AA, Rangel EF. Moonlight and blood-feeding behaviour of Lutzomyia intermedia and Lutzomyia whitmani (Diptera:Psychodidae: Phlebotominae), vectors of American Cutaneous Leishmaniasis in Brazil. Mem Inst Oswaldo Cruz. 2005;100:39-42. 